\title{
REVIEW
}

\section{NEUROMUSCULAR BLOCKADE IN CHILDREN}

\author{
João Fernando Lourenço de Almeida, W. Jorge Kalil Filho and Eduardo J. Troster
}

RHCFAP/3012

ALMEIDA J F L de et al. - Neuromuscular blockade in children. Rev. Hosp. Clín. Fac. Med. S. Paulo 55(3):105-110, 2000.

SUMMARY: Neuromuscular blocking agents (NMBAs) have been widely used to control patients who need to be immobilized for some kind of medical intervention, such as an invasive procedure or synchronism with mechanical ventilation. The purpose of this monograph is to review the pharmacology of the NMBAs, to compare the main differences between the neuromuscular junction in neonates, infants, toddlers and adults, and moreover to discuss their indications in critically ill pediatric patients. Continuous improvement of knowledge about NMBAs pharmacology, adverse effects, and the many other remaining unanswered questions about neuromuscular junction and neuromuscular blockade in children is essential for the correct use of these drugs. Therefore, the indication of these agents in pediatrics is determined with extreme judiciousness. Computorized (Medline 1990-2000) and active search of articles were the mechanisms used in this review.

DESCRIPTORS: Neuromuscular blocking agents. Neuromuscular blocking drugs. Neuromuscular junction. Neuromuscular block. Neonate. Infant. Child.

Since the introduction of the neuromuscular blocking agents (NMBAs) in 1942, a marked evolution has occurred in these drugs, with progressive increase in their potency combined with fewer risks or adverse effects. Many of these NMBAs have appeared in the last 10 years, with an increase in their use in intensive care units ${ }^{1}$. On the other hand, the development of new drugs has made the choice of agents much more complex, due to differences in pharmacology, clinical indications, and side effects of each new drug $^{2}$. The NMBAs have been routinely given to critically ill patients to facilitate tracheal intubation, for muscle relaxation during surgery (generally abdominal and thorax surgery) and to patients who offer resistance to mechanical ventilation (despite the use of intense analgesia and sedation).

In this review, we analyze the pharmacology of and indications for the old
NMBAs, and we also review the clinical and pharmacologic advances of the new agents as well as their complications.

\section{Physiology of neuromuscular trans- mission and blockade}

Definition: The neuromuscular blockade can be defined as a reversible interruption of neuromuscular transmission in the Acetylcholine (AcC) nicotinic receptors, fin the absence of any analgesic, sedative or amnesic action. In summary, the normal neuromuscular transmission is related to the stimulation of the postsynaptic junctional receptors of $\mathrm{AcC}$ that arouse the depolarization and muscular contraction $^{3,4}$. Nicotinic Receptors: The neu-

From the Department of Pediatrics, Hospital das Clínicas, Faculty of Medicine, University of São Paulo. romuscular junction contains some types of nicotinic receptors:

- Two on the muscle surface;

- one junctional;

- one extrajunctional;

- one presynaptic receptor on the parasympathetic-nerve ending ${ }^{5,6}$.

The postsynaptic receptors are proteins with five subunits: $\alpha, \beta, \chi, \delta$ e э. Each neuromuscular junction contains 1-10 million nicotinic receptors ${ }^{3,4,6}$.

Physiology of neuromuscular transmission: The neuromuscular transmission initiates when a nerve impulse arrives on the presynaptic nerve endings, with liberation of AcC molecules. The AcC-liberated molecule crosses the junctional cleft to stimulate the postsynaptic receptors.

To begin the opening of the channel receptors, which allow the movement of ions that will finally depolarize the end plate, $2 \mathrm{AcC}$ molecules must bind simultaneously to two a sub- 
units of a postsynaptic receptor. When this happens, a brief opening (1 msec.) of the channel occurs, with a non-selective passage of sodium and calcium to the muscle, leading to depolarization of the muscular membrane and muscular contraction.

Then the AcC molecule is quickly broken down by the enzyme acetylcholinesterase in the junctional cleft, stopping the muscular contraction ${ }^{6}$.

Physiology of the neuromuscular blockade: The neuromuscular blockade can exist by two distinct mechanisms:

- Depolarizing neuromuscular blockade;

The neuromuscular blockade by the classic pathway (depolarizing), begins when a drug bind to the a subunit of the nicotinic receptors like the molecule of $\mathrm{AcC}$ does. In the beginning, an initial opening of the ion channel produces a contraction (fasciculation). After this, the depolarization of muscular membrane is sustained (persistent depolarization), since the drug is not broken by acetylcholinesterase, leading to neuromuscular block.

- Nondepolarizing neuromuscular blockade;

In the nondepolarizing neuromuscular blockade, the drugs bind in a competitive way (with AcC) to at least one a subunit of the nicotinic receptors. Since there is no biding of at least two molecules of AcC, there is no opening of the ion channels and no muscular depolarization, with the muscle becoming flacid $^{6,7}$.

\section{Particularities of neuromuscular blockade in children}

There are some characteristic points in the neuromuscular junction that differentiate newborns and infants from other ages.

In the first 2 months of life (in particular the newborn), the neuromuscu- lar junction (NMJ) is still developing. In this maturation phase, the receptors have an increased metabolic activity.

The main point that distinguishes the immature receptors from the developed ones is a functional difference that occurs due to a prolonged opening of the ionic channels. This allows the immature muscles to be more easily depolarized, and these receptors have also a greater affinity for depolarizing agents and lower affinity for nondepolarizing agents $\mathrm{s}^{3,5,8,9}$.

One of the age-related particularities is the alteration in the degree of neuromuscular blockade with the body composition and the drug distribution. Since the NMBAs distribute in the extracellular fluid exclusively, and since neonates and infants have a larger extracellular compartment with a higher volume of distribution, neonates and infants require high doses of NMBAs to reach the desired effect. This difference is decreased in toddlers and school-aged children that have a volume of distribution close to Adults (figure 1$)^{5}$.

Concerning the alterations concerning the type of muscular fibers (type I, or slow-twitch, and type II, or fasttwitch), it is important to note that the type I fibers are more sensitive to NMBAs as compared to type II fibers. Type I fibers have clinical relevance, since the diaphragm of a neonate has fewer type I fibers as compared to a diaphragm of a toddler or a adult. This

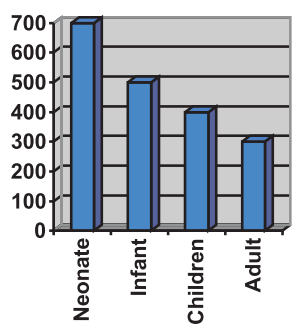

makes the diaphragm of a infant more reactive to NMBAs than his own peripheric musculature ${ }^{3}$.

\section{Classification of NMBAs}

The NMBAs are classified as follows:

1) Based on the pharmacologic mechanism:

a. Depolarizing drugs;

b. Nondepolarizing drugs.

2) Based on the biochemical structure:

a. Benzylisoquinolinium derivatives;

b. Aminosteroids compounds.

3) Based on the duration of the desired effect:
a. Short-acting drugs;
b. Intermediate-acting drugs;
c. Long-acting drugs.

The NMB drugs have many indications and adverse effects. For this reason, anaesthesiologists and intensivists are trying to systematize the choice of the "ideal NMBA", which has to: have rapid onset of action and ease of reversion; have low toxic levels; have few autonomic and cardiovascular effects; are metabolized and excreted independently of the final organic function; and have low cost.

\section{Depolarizing agents (agonists)}

Succinylcholine (Sch): Succinylcholine is considered a nondepo-

$$
\square \mathrm{Vdml} \mathrm{kg} \mathrm{-1)}
$$

Figure 1 - Age-related changes in the steady state volume of distribution (Vd) da D-tubocurarine (curare) parallel maturational changes in the volume of the extracellular fluid space (Vlec). (Fisher et al. $)^{5}$. 
larizing NMBA with short action and is the only nondepolarizing agent available for clinical use today. Due to its fast initial action, the main indication of this drug is for tracheal intubation (considered the first choice in recent review $)^{10}$. Succinylcholine $(\mathrm{Sch})$ is formed by 2 joined AcC molecules and rapidly hydrolyzes into succinic acid and choline by the (pseudo) cholinesterase in patients with normal levels of this enzyme.

Succinylcholine acts by stimulation of the cholinergic receptors (activation of the NM junction) that leads to depolarization of the musculature. This causes primarilly a muscular contraction or fasciculation.

Succinylcholine has an onset of action of 30 to 60 seconds and a duration of 3 to 5 minutes (I.V.). The typical blockade of Sch (or phase I blockade) is obtained in normal doses of 1 to $2 \mathrm{mg} / \mathrm{kg} / \mathrm{dose}$. In cumulative doses higher than 2 to $4 \mathrm{mg} / \mathrm{kg}$, a alteration in the type of blockade is obtained (competitive blockade or phase II blockade) with a nondepolarizing action. This drug has hepatic metabolism, and $10 \%$ of the drug is excreted unchanged in urine.

Some clinical situations can change the levels of the plasma cholinesterase, which can lead to prolonged neuromuscular blockade (Table 1).

The most important side effects and complications of Sch use are:

1) Complications related to depolarization (muscular fasciculation and pain, increase in the intracranial pressure, increase in the intragastric and intraocular pressure and displacement of compound fracture);
2) Prolonged neuromuscular blockade (plasma cholinesterase deficiency);

3) Cardiovascular effects (dysrhythmias - generally bradyarrhythmias in children, with recommendation to dispose of atropine for immediate use);

4) Anaphylaxis;

5) Myoglobinemia and myoglobinuria;

6) Hyperkalemia;

7) Malignant hyperthermia (associated with inhalation anesthetics) $)^{11,12,13}$.

\section{Nondepolarizing agents (antagonists)}

\section{Short action}

Mivacurium: Until the appearance of rapacuronium, mivacurium was the only nondepolarizing NMBA classified as a short-action drug. It is derivative from benzylisoquinolinium, with 3 times the potency of atracurium (which is a secondary derivative) ${ }^{14}$.

It has an onset of action of 1 to 3 minutes and duration less than $30 \mathrm{~min}$ utes. This drug is metabolized by plasma cholinesterase (and is altered in the same clinical situations mentioned in Sch). It is excreted in the urine. The normal dose is $0.2 \mathrm{mg} / \mathrm{kg} /$ dose.

The potential side effects are:

1) Prolonged neuromuscular blockade in cases of plasma cholinesterase deficiency or renal failure (metabolites with renal excretion);

2) Histamine release in rapid infusions (but with hypotension rarely observed $)^{3,6,15}$.

Rapacuronium: Rapacuronium is the newest non-depolarizing NMBA. This drug is not yet approved for clinical use by the FDA and is under clinical investigation in children. In adults, rapacuronium has shown an onset of

Table 1 - Clinical situations of diminished plasma cholinesterase.

\begin{tabular}{ll}
\hline Hepatic disease & Organophosphate \\
Infants until 2 months of life & Cyclophosphamide \\
Burns & Neostigmine \\
Extra-corporeal circulation & Malnutrition \\
Uremia & Plasmapheresis \\
\hline
\end{tabular}

action as rapid as succinylcholine, with decreased duration as compared to mivacurium. Recent studies show a similar effect in children, with little cardiovascular effects and histamine release $^{16}$.

\section{Intermediate action}

Atracurium: Atracurium is a bisquaternary intermediate NMBA (an ammonium benzylisoquinolinium). It has an onset of action of 2 minutes with a peak in 5 to 10 minutes. Its duration is about 40 to 60 minutes. Atracurium is metabolized by spontaneous degradation (Hoffman elimination), a non-enzymatic separation that occurs at normal temperature and $\mathrm{pH}$. Atracurium is degraded into acrylate and laudanosine, which are initiators of neuromuscular blockade. Laudanosine has been associated with central nervous system stimulation and convulsion.

The normal dose is 0.4 to $0.8 \mathrm{mg} /$ $\mathrm{kg} / \mathrm{dose}$ (initial) and 2 to $15 \mathrm{mcg} / \mathrm{kg} /$ minute (continuous infusion).

Hypotension and histamine release can be associated with rapid infusion of the drug. Cutaneous erythema is a common manifestation. Another disadvantage of atracurium is the necessity of higher doses in cases of prolonged use. Its main advantage is the difference in its metabolism and the possibility of use in patients with renal or hepatic failure ${ }^{3,6,14,17}$.

Cisatracurium: Cisatracurium is a cis-cis isomer of atracurium. It is a drug with the same characteristics of atracurium but stimulates less histamine release and less laudanosine production. It has 4 times the potency combined with low cost as compared with its isomer. Despite its advantages, there are a few studies about the use of this drug in adults and even fewer studies in children ${ }^{3,5,6}$.

Vecuronium: Vecuronium is a aminosteroid derivative of 
pancuronium, with an alteration in its structure (molecular position of 2 methyl N-piperidine). This structural alteration considerably reduces the vagolytic effects (tachycardia and hypertension) observed with pancuronium. It has an onset of action of 1 to 3 minutes and duration of 30 to 40 minutes (dose dependent). Vecuronium is metabolized $40 \%$ to $50 \%$ in the liver, and after hepatic hydrolysis, 3 of its metabolites have neuromuscular blocking activity (one of them with $70 \%$ of the action). These metabolites are excreted in the urine (with $15 \%$ of accumulation in patients with renal failure). Its main disadvantage is the prolonged neuromuscular blockade ${ }^{3,6,18}$.

The dose is 0.08 to $0.15 \mathrm{mg} / \mathrm{kg} /$ dose (initial) and 0.8 to $1.2 \mathrm{mcg} / \mathrm{kg} /$ minute (continuous infusion).

Rocuronium: Rocuronium is an aminosteroid derivative of vecuronium with intermediate-to-short action. It was recently approved for clinical use by the FDA (1990). It has the same characteristics of vecuronium with higher potency $(10 \%$ to $15 \%)$. This drug has minimal cardiovascular effects (just a little increase in cardiac frequency). ${ }^{19}$ The onset of action in children is about 30 to 60 seconds and the duration is 30 to 40 minutes (equal in children and adults). It is metabolized by the liver $(50 \%$ to $60 \%)$ with $33 \%$ excreted unaltered in the urine. Due to its fast onset of action in children, it is a good option for rapid sequence tracheal intubation ${ }^{10}$.

\section{Long action}

Pancuronium: Since its introduction in 1967, pancuronium has been the most used NMBA by anesthesiologists and intensivists. It is a synthetic aminosteroid that has an onset of action of 2 to 3 minutes and half-life of 110 minutes.
About $30 \%$ to $40 \%$ of this drug is metabolized by the liver, and it is excreted in the urine (with up to $40 \%$ unaltered drug, which could lead to prolonged neuromuscular blockade).

The recomended dose is 0.04 to 0.1 $\mathrm{mg} / \mathrm{kg}$.

Pancuronium has many side effects, most of them related to the cardiovascular system ( e.g., tachycardia, hypertension, increased cardiac output, all due to vagal block and norepinephrine release) ${ }^{3,20}$.

Doxacurium: Among the benzylisoquinolinium derivatives, doxacurium is the most recently approved for clinical use. It is the most potent NMBA (10 times more potent than d-tubocurarine) with slow action. It has an onset of action of 6 to $11 \mathrm{~min}$ utes and a duration of 60 minutes. This drug binds with plasma proteins $(30 \%)$ with minimum metabolism and is eliminated unaltered in the urine and bile.

The dose is 0.03 to $0.05 \mathrm{mg} / \mathrm{kg} /$ dose.

Doxacurium is a drug with few side effects, although it has been associated with prolonged neuromuscular blockade in patients with renal failure ${ }^{3,21}$.

\section{Indications and drug selection}

The main indications for the use of NMBAs are based on the optimization of immobility of the patient for procedures like:

- Short-term (less than 6 hours):

1) tracheal intubation;

2) high-risk invasive procedures.

- Long term (more than 6 hours):

1) synchrony with mechanical ventilation (dyssynchrony, excessive hyperventilation or h y p o v e $\mathrm{t}$ i 1 a $\mathrm{t}$ i o n, nonconventional ventilation);

2) reduction of metabolic demand or work of breathing;

3) treatment of intense agitation unresponsive to higher doses of analgesia and sedation;

4) therapeutic hypothermia (decreased shivering);

5) protection of surgical repairs.

It's important to remember that in all these indications, the use of NMBAs should be considered in patients that deep sedation and analgesia have failed to reach the desired effect.

The choice of the best NMBA becomes very difficult and dependent on the degree and necessity of the muscular relaxation desired. So the basic criterions should be followed when one is making the choice for the more adequate NMBA: patient's age, onset of action and duration of the drug (depending on the final goal), presence or absence of hemodynamic instability, association with other drugs, presence of organ failure (renal or hepatic); potential risks and side effects (in short and long term), presence of previous disease, and the drug's cost. Pharmacologic data about the main NMBAs are on Table 2.

In September of 1995, the Society of Critical Care Medicine published an official statement and best practice parameters for the use of NMBAs ${ }^{22}$. The 2 recommendations concerning the use of NMBAs were classified as level 2 or reasonably justifiable by available scientific evidence and strongly supported by expert critical care opinion. The first recommendation was to use pancuronium as the preferred NMBA for most critically ill patients, justified by the few adverse cardiovascular consequences and the low cost - an alert was given for the use in patients with renal or hepatic failure (to use lower doses). The second recommendation was to use vecuronium as the first option in patients with cardiac disease or hemodynamic instability, with lower doses in patients with renal or hepatic failure.

It is important to note that this con- 
Table 2 - Pharmacology of non-depolarizing NMBAs.

\begin{tabular}{|c|c|c|c|c|c|}
\hline & Pancuronium & Atracurium & Vecuronium & Doxacurium & Mivacurônio \\
\hline Year introd & 1972 & 1983 & 1984 & 1991 & 1988 \\
\hline Initial dose $(\mathrm{mg} / \mathrm{kg})$ & 0,1 & $0,4-0,5$ & 0,1 & 0,05 & 0,2 \\
\hline Duration (min) & $90-100$ & $25-3$ & $35-45$ & $120-150$ & $<30$ \\
\hline Continuous $(\mathrm{mcg} / \mathrm{kg} / \mathrm{m})$ & $1-2$ & $4-12$ & $1-2$ & $?$ & $1-15$ \\
\hline Reversion (min) & $120-180$ & $40-60$ & $46-60$ & $120-180$ & $15-20$ \\
\hline Histamine liber. & no & $\operatorname{minim} /$ dose dep & variable & $?$ & minim. \\
\hline Vagal block & important & no & no & no & no \\
\hline Gangl. block & no & minim. & no & no & no \\
\hline Prolong. NMB & yes & rare & yes & yes & yes \\
\hline Cost & low & interm./high & interm. & high & high \\
\hline
\end{tabular}

sensus was made for adult patients, and it must be carefully interpreted for pediatrics since the cardiac effects of pancuronium are very expressive in children.

\section{Monitoring the neuromuscular blockade}

Despite its difficulty in daily practice, the monitoring of the neuromuscular blockade should be used routinelly in intensive care units, due to the wide variations in the degree of blockade between the patients. It is very hard to identify the response exactly in terms of the beginning, the degree, and the duration of the neuromuscular blockade. Therefore, monitoring becomes important for documenting the presence and degree of blockade and the return of the normal neuromuscular transmission.

Monitoring of the effects of these drugs is done by the the stimulation of the ulnar nerve and observation of the evoked response in the adductor muscle by a force transductor, by electroneuromyography, or by visual inspection.

There are 3 patterns of nerve stimulation: 1) simple stimulus (0.1 to 0.15 $\mathrm{Hz})$; 2) train-of-four ( $2 \mathrm{hz}$ per $4 \mathrm{sec}-$ onds or 4 impulses of 0.5 second, repeated every 10 seconds), and 3) tetanic stimulus (50 to $100 \mathrm{~Hz}$ per $5 \mathrm{sec}$ onds) ${ }^{3,23}$.

\section{Complications of the use of NMBAs}

The great majority of complications after the use of NMBAs are associated with long term utilization.

In the last decade, the major described complication is the prolonged muscle weakness after its discontinuation. This complication is well documented in children, generally with the use longer than 48 hours. This effect could last for up to 6 months ${ }^{24}$. There are 2 patterns of neuromuscular dysfunction: the persistent block of the $\mathrm{NM}$ junction (PBNMJ) and the acute myopathy ${ }^{25}$.

PBNMJ is the complication that has more clinical significance, probably due to the accumulation of drugs or its active metabolites (mainly in patients with renal or hepatic failure). Another pattern of PBNMJ is the one that begins when an aminosteroid NMBA and corticosteroids are used together ${ }^{26,27}$. This association of drugs is important since one of the major indications of NMBAs in pediatrics is the child with status asthmaticus with dyssynchrony with mechanical ventilation (and who uses short or long-term corticosteroids). This kind of PBNMJ was also recently described with the association of benzylisoquinolinium derivatives and corticosteroids ${ }^{28}$.

The acute myopathy also leads to prolonged paralysis, but is not caused by delayed recuperation of the NM junction ${ }^{25}$.

Muscular atrophy, joint contractures, thrombotic or embolic events, ulcers of the skin, atelectasis, pneumonia, and corneal drying are other possible complications. Special attention should be given to the neurologic evaluation of the patient receiving NMBAs (attention to status epilepticus and monitoring with electro-encephalogram) and the assessment of pain and anxiety (sweaty brow, tearing, hypertension, and tachycardia could be signs of pain or anxiety) $)^{3,5,6,9}$.

With the knowledge of all these complications, the NMBAs shoud be used only when profound analgesia and sedation have failed to reach the desired effect and when used, bolus doses are preferred and continuous and prolonged infusions should be avoided.

\section{Final considerations}

The NMBA continue to be frequently used drugs in pediatric intensive care units. Continuous updating concerning the pharmacology of the NMBAs (mainly the new ones) is necessary for the correct evaluation of the indications for each drug and to avoid adverse effects. Many questions about the physiology of the neuromuscular junction and about the NMBAs and their complications in children remain unanswered, which indicates a very judicious use of these drugs in children. 
ALMEIDA J F L de e col. - Bloqueadores neuromusculares em crianças. Rev. Hosp. Clín. Fac. Med. S. Paulo 55(3):105-110, 2000.

Os bloqueadores neuromusculares têm sido amplamente utilizados para controlar pacientes que necessitem imobilidade para algum tipo de intervenção médica, desde a realização de procedimentos invasivos até a obtenção de sincronismo com a ventilação mecânica. O objetivo básico desta monografia é revisar a farmacologia dos principais bloqueadores neuromusculares, analisar as diferenças existentes na junção neuromuscular de neonatos, lactentes, pré-escolares e adultos, além de discutir suas indicações em pacientes criticamente enfermos internados em unidade de terapia intensiva pe- diátrica. Revisão computadorizada da literatura (Medline 1990-2000) associado a busca ativa de artigos compuseram o mecanismo de busca dos dados desta revisão.

DESCRITORES: Bloqueadores neuromusculares. Junção neuromuscular. Bloqueio neuromuscular. Neonatos. Lactentes. Crianças.

\section{REFERENCES}

1. MURRAY MJ, STRICKLAND RA \& WEILER C - The use of neuromuscular blocking drugs in the intensive care unit: A US perspective. Intensive Care Med 1993; 19:S40-S44.

2. MARTIN LD, BRATTON SL \& O'ROURKE PP - Clinical uses and controversies of neuromuscular blocking agents in infants and children. Crit Care Med 1999: 27(7): 1358-1368.

3. MARTIN JAJ, WHITE DA, GRONERT GA et al. - Up and down regulation of skeletal muscle acetylcholine receptors. Anesthesiology 1992; 76: 822-843.

4) RAMA SASTRY BV - Nicotine receptor. Anaesth Pharmacol Rev 1993; 11:219-236.

5. FISCHER DM - NMBA in paediatric anaesthesia. Br J Anaesth 1999; 83(1):58-64

6. HUNTER JM - New neuromuscular blocking drugs. N Engl J Med 1995; 332(25): 1691-1699.

7. RAMSEY FM - Basic Pharmacology of neuromuscular blocking agents. Anesth Clin North Am 1993; 11:219-236.

8. GOUDSOUZIAN NG - Maturation of the neuromuscular transmission in infant. Br J Anaesth 1980; 52:205-213.

9. GRONERT BJ \& BRANDOM BW - Neuromuscular Blocking Drugs in Infants and Children. Ped Anesth 1994; 41:73-91.

10. McALLISTER JD \& GNAUCK KA - Rapid Sequence Intubation of the Pediatric Patient - Fundamentals of Practice. Pediatr Clin North Am 1999; 46(6): 1249-1284.

11. OREBAUGH SL - Succinylcholine: Adverse Effects and Alternatives in Emergency Medicine. Am J Emerg Med 1999; 17(7): 715721.

12. BASTA SJ - Modulation of histamine release by neuromuscular blocking drugs. Curr Opin Anaesthesiol 1992; 5:572-576.

13. PRIELIPP RC \& COURSAN DB - Applied Pharmacology of Common Neuromuscular Blocking Agents in Critical Care. New Horizons 1994; 2:34-47.

14. BELMONT MR et al. - Pharmacodinamics and pharmacokinetics of benzylisoquinolinium (curare-like) neuromuscular blocking drugs. Anesth Clin North Am 1993; 11:251-283.

15. MIRAKUR RK - Neuwer neuromuscular blocking drugs: a overview of their clinical pharmacology and therapeutic use. Drugs 1992; 44:182-199.

16. KAPLAN RF, FLETCHER JE, HANNALLAH RS et al. - The Potency (ED50) and Cardiovascular Effects of Rapacuronium (Org 9487) During Narcotic-Nitrous Oxide Propofol Anesthesia in Neonates, infants and Chlidren. Anesth Analg 1999;89:1172-6.
17. BASTA SJ, SAVARES JJ, ALI HH et al. - Histamine release potencies of atracurium and dimethyl-tubocarine. Br J Anaesth 1983;55:105S$111 \mathrm{~S}$.

18. MEISTELMAN C, AGOSTON S, KERSTEN UW et al. Pharmacokinetics and pharmacodynamics of vecuronium and pancuronium in anesthetized children. Anesth Analg 1986;65:13191323.

19. WRIGHT PMC et al. - Onset and duration of rocuronium and succinylcholine at the adductor pollicis and laryngeal adductor muscles in anesthetized humans. Anesthesiology 1994;81:11101115.

20. LEMOS JM, CARR RR, SHALANSKY KF et al - Paralysismin the critically ill: Intermittent bolus pancuronium compared with continuous infusion. Crit Care Med 1999;27(12):2648-2655.

21. BASTA SJ, SAVARES JJ, ALI HH et al - Clinical pharmacology of doxacurium chlotide: a new long-acting non-depolarizing musclerelaxant. Anesthesiology 1988;69:478-486.

22. SCCM - Practice Parameters for Sustained Neuromuscular Blockade in the Adult Critically Ill Patient: Official Statement of the Society of Critical Care Medicine. 1995.

23. DAVIDSON JE - Neuromuscular blockade: Indications, Peripheral Nerve Stimulation and other concurrent interventions. New Horizons 1994;2:75-84.

24. WOKKE JHJ, JENNEKENS FGI et al. - Histological investigations of muscle atrophy and end plates in two critically ill patients with generalized weakness. J Neurol Sci 1988;88:95-106.

25. WACLAWIK AC, SUFIT RL, et al. - Acute myopathy with seletive degradation of myosin filaments following status asthmaticus. J Neurol Sci 1990;98(Suppl:470)

26. HIRANO M, OTT B,RAPS E, et al. - Acute quadriplegic myopathy: a complication of treatment with steroids, nondepolaring blocking agents or both. Neurology 1992;42:2082-2087.

27. LARSSON L et al. - Acute quadriplegia and loss of muscle myosin in patients treated with ND-NMBA and corticosteroids: Mechanisms at the cellular and molecular levels. Crit Care Med 2000; 28(1): 34-45.

28. MEYER KC et al. - Prolonged weakness after infusion of atracurium in two intensive care unit patients. Anesth Analg 1994; 78:772-774.

29. SCHVARTSMAN S \& SCHVARTSMAN C - Pronto Socorro de Pediatria. $2^{\circ}$ ed. São Paulo, Sarvier 1999. c. 6.

Received for publication on the $03 / 05 / 00$ 